\title{
Estudio Comparado para la Evaluación Cualitativa del Sistema de Cooperación Internacional de Chile
}

\author{
Matías Urrutia \\ Agencia de Cooperación Internacional de Chile
}

\begin{abstract}
Resumen
El objetivo del presente trabajo fue realizar un análisis comparativo, a nivel de estructura y de funciones, de los sistemas de cooperación internacional de Chile, España y Portugal, para esto se utilizó una metodología de comparación basada en un modelo teórico ya elaborado por el Instituto Latinoamericano y del Caribe de Planificación Económica Social (ILPES). Como conclusión, cabe afirmar que, si bien, el Sistema de Cooperación de Chile cuenta con la mayor parte de los componentes que requiere para ser catalogado como ?funcional?, se identificaron nodos críticos de estructura, en las áreas de coordinación horizontal del sistema, y de gestión, relacionados con una disociación entre el nivel estratégico y los niveles programáticos y operativo.
\end{abstract}

Palabras clave: Cooperación internacional, metodologías comparadas, estructura organizacional.

\section{Comparative Study for Qualitative Evaluation of the International Cooperation System} in Chile

\begin{abstract}
The aim of this study was to carry a comparative analysis at the level of structure and functions of the international cooperation systems in Chile, Spain and Portugal. For this, a comparison methodology based on a theoretical model already developed by the Institute Latin American and Caribbean Economic and Social Planning (ILPES) was used. In conclusion, although the Cooperation System of Chile has most of the components required to be classified as "functional" there are critical structure nodes that were identified in the areas of horizontal coordination of the system and management, related to a dissociation between the strategic level and programmatic and operational levels.
\end{abstract}

Keywords: International cooperation, comparative methodologies, organizational structure.

\section{El Sistema de Cooperación In- ternacional de Chile}

El traspaso de Agencia de Cooperación Internacional de Chile a las dependencias del Sistema Nacional de Relaciones Exteriores, significó un gran cambio de enfoque respecto a la forma de ejecutar la cooperación internacional del país. Sin embargo, en la medida que el escenario internacional ha ido cambiando y los foros y diálogos de cooperación han instalado nuevos requisitos y necesidades, ha quedado cada vez más en evidencia la necesidad de adaptación del sistema organizacional encargado de

*Dirección de correspondencia [Correspondence address]:

Matías Urrutia, Agencia de Cooperación Internacional de Chile

E-mail: murrutia@agci.cl la gestión de la cooperación internacional.

Tanto la evolución del país, como las nuevas prioridades del sistema global de cooperación internacional, suponen un stress a la estructura organizacional nacional, particularmente a su núcleo, que en este caso es la Agencia de Cooperación Internacional de Chile. Es por esta razón que el objetivo de esta investigación es analizar las principales características e identificar las principales debilidades del Sistema Nacional de Cooperación Internacional como un sistema de cooperación funcional, capaz de responder a las demandas de sus "clientes" y a los objetivos de las políticas públicas que lo determinan; tanto desde una perspectiva estructural como de gestión. Se plantea, de esta forma, la siguiente pregunta de investigación: ¿Existen nodos críticos de gestión y estructura la interior del órgano rector que dificulten el cumplimiento de las necesidades y los objetivos de la política de cooperación y política exterior por parte del sistema nacional de cooperación internacional? 


\section{Cooperación Internacional y Coope- ración Sur-Sur}

En este artículo se entiende la Cooperación Internacional como "la relación que se establece entre dos o más países, organismos u organizaciones de la sociedad civil, con el objetivo de alcanzar metas de desarrollo consensuadas" (RACI, 2012). Esta se desarrolla mediante una serie de herramientas que han ido evolucionando con el trascurso del tiempo (RACI, 2012).

Respecto a la evolución de las herramientas de la cooperación, desde fines de los ochenta y durante la década de los 90 (periodo marcado por el contexto post-guerra fría y el auge de la globalización), los procesos de integración económica se intensificaron y el espacio geopolítico nacional se vio superado para enfrentar los problemas generalizados del subdesarrollo, propiciando su desnacionalización. Este proceso se dio acompañado de la denominada "fatiga o cansancio de la ayuda" (Colacrai et al., 2009). Esta idea, planta los problemas más dramáticos del subdesarrollo no pueden ser superados mediante las transferencias directa de recursos, razón por la cual en esta década surgió la condicionalidad en la cooperación Ayuda Oficial al Desarrollo (AOD), estableciendo requisitos como la implementación de reformas político-institucionales para recibir transferencias. Fue, precisamente, en este contexto de restricciones, que se presentó un importante espacio para la Cooperación Sur-Sur ${ }^{1}$ (CSS), la cual supone la transferencia de conocimiento y experiencias como el principal instrumento para apoyar al desarrollo. Aunque su aparición se impuso como una alternativa a las restricciones a la cooperación, en el largo plazo terminó por posicionarse como una modalidad complementaria a la AOD.

Finalmente, el siglo XXI ha sido el periodo de institucionalización de la cooperación. Los cambios ocurridos a fines del siglo anterior; como el fortalecimiento de la CSS, la instalación de los problemas críticos de la humanidad a nivel global y las crisis económicas del periodo que evidenciaron las debilidades del consenso de Washington; incentivaron a la comunidad internacional a realizar una serie de foros en los cuales se fijaron compromisos que definieron los lineamientos de la cooperación internacional.

El panorama internacional actual, dibuja una nueva arquitectura para la Cooperación Internacional en general y la CSS en particular. Por una parte, los problemas globales siguen siendo un desafío, y si bien al 2010 se logró reducir la pobreza a la mi-

\footnotetext{
${ }^{1}$ Tipo de cooperación que desarrolla Chile en la actuali-
}

tad a nivel global, aún queda mucho por avanzar en el África Subsahariana (Olinto et. al. 2013, citado en Domínguez y Olivié, 2014), junto con otros objetivos del milenio como la enseñanza primaria universal, mejorar la salud materna, garantizar la sostenibilidad del medio ambiente, entre otros.

Por otra parte, la aparición de la "paradoja de la pobreza", que dice relación con que la mayor parte de la población pobre a nivel mundial no se encuentra en los países más pobres, sino en los de Renta Media (Domínguez y Olivié, 2014; RACI, 2012; Sumner, 2010), ha desdibujado la lógica de la cooperación, pues si la mayoría de los pobres globales no se encuentran en los de países de renta baja, entonces es necesaria una renovación de argumentos de la cooperación en congruencia la nueva agenda post-2015. Adicionalmente, muchos de estos Países de Renta Media, que se proyectan para ser los que "que conduzcan el crecimiento" para el 2025 (Banco Mundial, 2013:39) ${ }^{2}$, son activos proveedores de CSS (Brasil y México son importantes actores en este escenario). Esta situación, ha roto el oligopolio de la ayuda del Comité de Ayuda al Desarrollo, dando heterogeneidad al panorama de "proveedores" de cooperación (Domínguez y Olivié, 2014).

Con respecto a la CSS, esta se encuentra "fragmentada" en 3 grupos: En primer lugar, se encuentran los BRICS ${ }^{3}$, que buscan generar un espacio para su cooperación para el posicionamiento de una identidad común relacionada con el desarrollismo y la oposición de una hegemonía dominante con el fomento del multilateralismo (Mielniczuk, 2013; Domínguez y Olivié, 2014). En segundo lugar, se encuentran países como Indonesia, Turquía, México, Colombia, Perú y Chile (estos últimos 4 integran la Alianza del Pacífico), que parecieran estar más dispuestos a seguir las reglas y disciplina estadística y programática del Comité de Ayuda al Desarrollo. Finalmente, se encuentran países como Venezuela y Cuba, cuyo enfoque más ideologizado, buscan un posicionamiento regional y contra-hegemónico (Domínguez y Olivié, 2014).

En conclusión, si bien existen ciertos consensos generales respecto a lo que se entiende por cooperación internacional, en la práctica, dada la multiplicidad de objetivos que se pueden perseguir mediante la ejecución de ésta, la definición del concepto no es simple ni univoca. Por esta razón, definir una política de cooperación no es tarea sencilla, aunque si es posible plantear ciertas características gene-

\footnotetext{
${ }^{2} \mathrm{La}$ OCDE (2010), proyecta que para el 2030, el $57 \%$ del PIB mundial será contribuido por los países no OCDE, a diferencia del $42 \%$ que aportaban el 2000 dando distinto peso relativo a cada uno.

${ }^{3}$ La sigla BRICS denota a las cinco economías nacionales emergentes más importantes del mundo. Estas son Brasil, Rusia, India, China y Sudáfrica.
} 
rales que permitan su adecuado análisis. En este sentido, una política de cooperación puede ser entendida como el set de instrumentos y ámbitos de acción de cooperación elegidos por un país para su participación en el sistema internacional, a fin de lograr los objetivos definidos en su agenda, además de aportar a logro de las metas de desarrollo consensuadas.

\section{El enfoque de estructuras y sistemas en las organizaciones públicas}

Las políticas públicas son materializadas o implementadas por sistemas organizacionales, los cuales buscan generar efectos o resultados deseados y sostenibles en el tiempo. Para hacer esto, los sistemas públicos se articulan mediante una serie de estructuras específicas, las cuales cumplen funciones concretas a fin de darle sostenibilidad. Más aún, las estructuras y sistemas organizacionales pueden ser protagonistas, llegando a cumplir la labor de describir e incluso definir y re-definir constantemente a las políticas públicas, a través del desarrollo de su labor.

\section{Manejo de la Estructura}

El enfoque basado en el modelo de Minzberg plantea que las organizaciones desarrollan, o deben desarrollar, su estructura en función de su contingencia y las interrelaciones lógicas entre sus distintas partes, identificadas como:

a) Núcleo de operaciones: Corresponde a la primera línea de trabajo que abarca a todos los miembros que realizan el trabajo de elaboración del producto o servicio principal de la organización, el cual se entrega directamente a la comunidad.

b) Cumbre o Ápice estratégico: Ubicado en el otro extremo organizacional, la cual abarca a "todas las personas encargadas de una responsabilidad general de la organización" (Mintzberg, 1988:50). Generalmente, comprende al Director de la organización y todos sus gerentes de división o alto nivel, cuyos intereses son más bien globales. Se ocupa de la efectividad organizacional, así como también satisfacer las necesidades de los stakeholders organizacionales.

c) Línea media: Es la cadena que une a los altos directivos con el Nivel Operacional. Este eslabón depende del tamaño de la organización y las necesidades de supervisión, lo que significa que el fortalecimiento de este tiene relación directa con la tendencia de la organización hacia la jerarquía vertical o hacía de horizontalidad organizacional.

d) La tecnoestructura: Está constituido por analistas y personal administrativo que son ajenos al flujo de trabajo operativo y solo sirven a la organización afectando al trabajo de otros. Según Katz y Kahn (1977), se encarga tanto de la adaptación, el cambio de la organización en función de la evolución del entorno, como del control la estabilización o estandarización de tareas y la normalización de las pautas de actividad en la organización.

e) Staff de apoyo: Corresponden a personas y unidades especializadas en la entrega de servicios indirectos a la organización, sin formar parte del proceso de producción del bien o servicio, al igual que la tecnoestructura. Se trata de unidades de apoyo como las de asesoría legal, servicios generales, seguridad, remuneraciones, administración de recursos humanos, etc. Estas unidades de apoyo se encuentran en distintos niveles jerárquicos, dependiendo de quienes sean sus clientes.

f) Ideología o cultura: Finalmente, tanto dentro como fuera de la organización existe un conjunto de valores y creencias que influyen sobre el esqueleto de la organización y la forma en que esta divide el trabajo para el manejo de insumos. Comúnmente conocida como cultura organizacional.

La predominancia e injerencia de cada uno de estos elementos, dan paso a diversos modelos y formas de configuración organizacional. Sin embargo, dichas áreas, si bien dan cuenta de la forma organizacional, no explican por sí mismas la función de la misma. Para esto, Mintzberg (1988) plantea que es necesario considerar el diseño, el cual influye tanto en la división del trabajo, como en los mecanismos de coordinación. En cuanto a dichos parámetros de diseño organizacional, se establecerá para el análisis los siguientes:

a) La especialización del trabajo.

b) La formalización del comportamiento.

c) La formación y adoctrinamiento.

d) Los sistemas de planificación y control.

e) Los dispositivos de enlace.

f) La descentralización del poder para la toma de decisiones.

Rev. Est. de Políticas Públicas, 2016, vol. 3 (junio) 
Finalmente, y para tener claridad respecto al comportamiento organizacional, se debe tener en cuenta ciertas consideraciones de contexto, las que terminan por dar forma a la estructura, tales como: 1) la edad y el tamaño de la organización, 2) las características de los sistemas técnicos de producción, 3) el grado de control externo de la organización y 4) el entorno económico e institucional de mercado u otras agencias del sector público (Pacheco, 2012).

\section{Enfoque de Sistemas}

Por su parte, los autores Daniel Katz y Robert Kahn (1977), desarrollaron un modelo de análisis sistémico de las organizaciones, en el cual plantearon que todo sistema organizacional que produce algún bien o servicio, contiene una serie de subsistemas o estructuras que realizan funciones específicas y que interactúan tanto entre sí como con el ambiente en un contexto determinado, definiendo a la institución en su conjunto.

Las estructuras presentadas son:

a) Subsistema de producción: Encargada de los procesos de línea del sistema, vale decir generar un bien o servicio que dice relación con algún aspecto de la tarea central del sistema. Esta estructura es la que genera el bien o servicio entregado al receptor final, el cual explica o define la tarea central del sistema completo.

b) Subsistema de mantención: Se encarga de "mantener la estabilidad y la capacidad de predicción en la organización" (Katz y Kahn, 1977:100). Vale decir, generar mecanismos que estandaricen los procesos, ya sea de línea o de soporte y que los hagan sostenibles en el tiempo. La estructura, utiliza diversos mecanismos, como generar estándares, establecer procedimientos y diseñar mecanismos de incentivos y correctivos a fin de que la conducta de los individuos sea la requerida por el sistema.

c) Subsistemas limítrofes de abastecimiento y ventas: Encargado del abastecimiento de materias primas para la producción del bien o servicio a entregar. No obstante también tienen una segunda función, la cual es "apoyar en las estructuras de producción y se relacionan con los intercambios transaccionales hechos con el ambiente" (Katz y Kahn, 1977:103), vale decir se encargan de influir sobre los compradores.

d) Subsistema de Adaptación: En oposición a la estructura de mantención, ésta se encarga de resolver problemas de ajuste de la organización dada su necesidad de supervivencia en un entorno cambiante (Katz y Kahn, 1977:103).

e) Subsistema de Gerencia: Vale decir la alta gerencia del sistema organizacional. Es transversal a todas las demás estructuras y se encarga de la "organización y de sus partes, que controla o que toma las decisiones" (Katz y Kahn, 1977:107). La estructura gerencial, si bien cumple una función organizacional, también es común que albergue funciones de tipo adaptativas (Katz y Kahn, 1977:1989). Otra función de la gerencia es resolver o contener los conflictos internos pues, las demás estructuras generan dinámicas de funcionamiento. No obstante esta no es su única función resolutiva, también debe atender las presiones ambientales, vale decir, "coordinar los requerimientos venidos del exterior con los recursos y necesidades de la organización" (Katz y Kahn, 1977:108).

En consecuencia, dado que el sistema gerencial se ve enfrentado a esta dualidad de funciones, es que los autores plantea que la estructura gerencial puede subdividirse en:

- Subsistema Gerencial: Encargado de la gestión y distribución de recursos al interior del sistema organizacional.

- Subsistema Institucional: Encargado de la toma de decisiones y resolver los problemas relacionados con las relaciones externas.

- Subsistema Técnico: Por último, se plantea la existencia de este subsistema subyacente a los otros dos, dedicado a las decisiones técnicas pertenecientes a las otras estructuras.

Finalmente, el proceso de coordinación interorganizacional debe darse entre los distintos niveles de la estructura organizacional, desde el ápice estratégico, hasta el núcleo de operaciones. Esto involucra una serie de aspectos, entre los que se cuentan los mecanismos de coordinación, la definición de roles y áreas de competencia de las organizaciones, entre otros. El que este proceso no se desarrolle adecuadamente, vale decir que no exista una adecuada coordinación, puede significar altos costos de transacción en la producción de los productos de la política, así como ineficiencias e ineficacias en la misma (Pacheco, 2012).

Por su parte, los mecanismos de coordinación adecuados, permiten mejorar la toma de decisiones por parte de las organizaciones involucradas que se nutren de la transferencia de insumos. Adicionalmente, este proceso mejorará aún más si los 
flujos de información dentro de cada organización son efectivamente fluidos, disminuyendo así las asimetrías de información.

\section{Metodología}

Esta investigación tiene una perspectiva comparada con un enfoque mixto (cualitativocuantitativo) de tipo exploratorio-descriptivo, el cual se centra en el análisis de los Sistemas de Cooperación Internacional de los países a investigar, desde las perspectivas de la Dinámica de los Subsistemas de las Organizaciones (Katz y Kahn, 1977) y de la Estructura de los Organismos (Mintzberg, 1988).

El estudio tiene tres fuentes de información:

- En primer lugar, se llevó a cabo una revisión bibliográfica de fuentes tanto primarias como secundarias, a fin de cubrir todo el espectro teórico que sustenta este documento. Por otra parte, se llevaron a cabo entrevistas de tipo semiestructuradas a María Cristina Lazo, Ex Directora y actual Consejera de AGCI, Eugenio Perez, actual Jefe (s) del Departamento de Coordinación de AGCI, Ana Maria Portales, actual Jefe de Departamento de Política y Planificación de $\mathrm{AGCI}^{4}$ y Claudio Prim, Encargado de Cooperación Internacional de FOSIS; todos actores claves vinculados a la cooperación internacional.

- En segundo lugar se revisaron los antecedentes formales de las instituciones a cargo de la cooperación internacional de España, Portugal y Chile. Esto, pues la comparación de los dos primeros (ambos son sistemas de cooperación consolidados, cercanos a Latinoamérica y al sistema de cooperación sur-sur debido a su participación en la Secretaria General Iberoamericana) con el sistema nacional permite vislumbrar aquellos elementos estructurales e instrumentales ausentes en nuestro sistema de cooperación internacional.

Finalmente, se realizó una encuesta de evaluación de las condiciones estructurales y de gestión existentes en el sistema chileno de cooperación, aplicada en línea a 23 funcionarios profesionales de los departamentos y unidades de línea de la Agencia de Cooperación Internacional de $\mathrm{Chile}^{5}$, los cuales

\footnotetext{
${ }^{4}$ Jefe subrogante al momento de la entrevista

${ }^{5}$ Departamento de Cooperación horizontal, Departamento de Cooperación Bimultilateral, Departamento de Formación y Becas y el Área de Política.
}

corresponden al 23,71\% de la dotación completa de la institución y al $57,5 \%$ de los funcionarios de dichos departamentos (incluyendo jefaturas y personal administrativo). A nivel de divisiones, 7 funcionarios corresponden al departamento de Cooperación Técnica entre Países en Desarrollo o Cooperación Horizontal (que equivalen al 77,8\% del departamento sin considerar a la jefatura y a la secretaría), 4 al área de Política del Departamento de Política y Planificación (que equivalen al $100 \%$ del área y al 36,4\% del Departamento, sin considerar a la jefatura y a la secretaría), 4 a la Unidad de Becas Horizontales del Departamento de Formación y Becas (que equivalen al 100\% del área y al 57,1\% del departamento, sin considerar a la jefatura y a la secretaría), 4 al Departamento de Cooperación Bimultilateral (que equivalen al $80 \%$ del departamento, sin considerar a la jefatura y a la secretaría) y 4 al Departamento de Coordinación (que equivalen al 57,1\% del departamento, sin considerar a la jefatura y a la secretaría) .

\section{Descripción de la encuesta aplicada}

La encuesta se estructura como una matriz de análisis, que pretende identificar nodos críticos mediante el análisis, por una parte, de las dimensiones "instrumentos", "estructura" y "articulación" a nivel departamental, organizacional y sistémica; y, por otra parte, de la dimensión de "modalidades de cooperación" y "ámbitos de acción" desde una perspectiva sistémica.

El cuestionario consiste en veintinueve afirmaciones positivas cerradas, respecto a las cuales los encuestados deben evaluar los elementos mencionados en una escala de 1 a 5 , donde la nota uno corresponde al total desacuerdo, la nota tres se corresponde a un punto intermedio, la cinco, a totalmente de acuerdo y, por último, la nota cero corresponde a "no sabe". Para el procesamiento de los datos de la encuesta se utilizó el programa Excel, con el cual se calculó la moda en cada pregunta y se determinó la distribución en las evaluaciones de los encuestados a las afirmaciones para obtener conclusiones preliminares, las que fueron contrastadas con los resultados obtenidos del análisis cualitativo previo.

\section{Descripción de la tabla de compara- ción y las variables de análisis}

Para desarrollar esta tabla de comparación, se tuvo como referencia el modelo diseñado por Juan Francisco Pacheco del ILPES para el estudio del sistema de planificación. Al respecto, se ha planteado la estructura de la tabla en dos ejes de los cuales se 
destacan: La primera parte para el órgano rector y la segunda parte para el sistema de cooperación en su conjunto.

Con el fin de averiguar la existencia de cada componente, se revisaron los marcos legales de los sistemas de cooperación, tanto de Chile como de España y Portugal, así como distintos documentos de trabajo y otro material informativo (incluyendo breves entrevistas no estructuradas) que diesen cuenta de la metodología de trabajo de los sistemas de los países en cuestión y del nivel de funcionamiento de sus estructuras organizacionales. En este sentido, se definieron tres niveles de evaluación:

- No existe la estructura o la función.

- No existe la estructura/instrumento/mecanismo/modalidad/ámbito pero la carencia es suplida o bien existe la estructura/instrumento/mecanismo/modalidad/ámbito, pero su utilidad es limitada.

- Existen la estructura y la función.

Respecto a los componentes de la tabla de comparación, para el órgano rector se presenta de la siguiente forma: En primer lugar, el órgano rector con las distintas direcciones esenciales que debe cumplir, seguido por instrumentos de trabajo con los que cuenta o debiese contar a fin de realizar eficientemente su trabajo y, finalmente, las relaciones que este órgano rector debiese mantener con el resto del sistema para ser más eficiente. En segundo lugar, el Sistema de Cooperación Internacional ha sido planteado según el enfoque sistémico del modelo teórico, por lo cual, se revisó la existencia de las estructuras globales de la teoría general de sistemas en organizaciones. En tercer lugar, se revisaron los ámbitos de acción o las líneas de acción que realiza cada sistema para ejecutar, de la forma más completa posible, su modelo de cooperación internacional para el desarrollo. Por último, se revisaron los instrumentos de planificación que deben estar presentes en cada sistema para desarrollar de la mejor manera posible sus respectivas políticas de planificación.

\section{Resultados}

\section{Evaluación al sistema nacional}

La estructura del sistema de cooperación chileno cuenta tanto con un órgano rector, la Agencia de
Cooperación Internacional de Chile, inserta y vinculada verticalmente con el Ministerio de Relaciones Exteriores. Este represente el núcleo coordinador desde el cual debiese pensarse el sistema como con un sistema organizacional, el cual opera mediante distintos mecanismos y ámbitos de acción.

\section{Análisis de la estructura, instrumentos y me- canismos de articulación del órgano rector}

De acuerdo al modelo teórico presentado, el órgano debiese contar con 8 direcciones ${ }^{6}$ específicas más una Dirección General. No obstante, la AGCI adolece de una de ellas, la de Acción o Ayuda Humanitaria. Dicha ausencia pareciera obedecer al lineamiento de una cuasi-política de cooperación, pues, tal como evidencian los expertos entrevistados, la necesidad de vincular a la ayuda humanitaria con la cooperación internacional no ha sido definida a nivel político.

Por su parte, en el caso de España, su sistema solo carece de la Dirección de Coordinación, cuya función, sin embargo, pareciera ser desarrollada por el Departamento de Cooperación Sectorial y la Secretaria General. Por otro lado, Portugal adolece de una Dirección de Coordinación y de Direcciones de Cooperación Territorial, no obstante esta función se encuentra a cargo de la División de Servicios de Cooperación. Si bien no existe una Unidad Ayuda Humanitaria, la función se encuentra a cargo de la División de Apoyo a la Sociedad Civil, dependiente de la División de Servicios de Cooperación.

Con respecto a los instrumentos que debería desarrollar el órgano rector para la adecuada ejecución de una estrategia de cooperación, la AGCI adolece de dos elementos. En primer lugar, no existen planes sectoriales de cooperación y en segundo lugar, la institución no posee Instrumentos operativos de monitoreo y evaluación de proyectos ejecutados o en ejecución.

Respecto a las otras dos estructuras de cooperación; Portugal, si bien carece de instrumentos programáticos de monitoreo y evaluación, la función es realizada y se planifica mediante los mismos Planes Indicativos de Cooperación con apoyo de la metodología de gestión de riesgo institucional.

Finalmente, en lo relativo a la articulación del órgano rector con el sistema, la Agencia posee es-

\footnotetext{
${ }^{6}$ Dirección Ejecutiva o General, Dirección de Cooperación Bilateral y Multilateral, Direcciones de Cooperación Territorial, Dirección de Administración y Finanzas, Dirección de Coordinación, Dirección de Formación / Difusión Cultural, Dirección de Política y Planificación, Auditoria Interna (Control Interno Contable y de Procesos) y Dirección de Acción/Ayuda Humanitaria.
} 
Figura 1: Tabla de Comparación de la Estructura del Órgano Rector de los Sistemas de Cooperación de Chile, España, Portugal e Ideal

\begin{tabular}{|c|c|c|c|c|c|}
\hline & VARIABLES & Chile & España & Portugal & Ideal \\
\hline \multirow{7}{*}{ Órgano rector } & Dirección Ejecutiva o General & & & & \\
\hline & Dirección de Cooperación Bilateral y Multilateral & & & & \\
\hline & Dirección de Administración y Finanzas & & & & \\
\hline & \begin{tabular}{|l|l|l} 
Dirección de Coordinación \\
\end{tabular} & & & & \\
\hline & Dirección de Formación / Difusión Cultural & & & & \\
\hline & Auditoria Interna (Control Interno Contable y de Procesos) & & & & \\
\hline & Dirección de Acción/Ayuda Humanitaria & & & & \\
\hline \multirow{4}{*}{ Instrumentos } & Presupuesto para la Cooperación & & & & \\
\hline & Estrategia plurianual de cooperación (desagregada de la Política) & & & & \\
\hline & Planes Sectoriales & & & & \\
\hline & Instrumentos Operativos Monitoreo y de Evaluación de Proyectos & & & & \\
\hline \multirow{4}{*}{$\begin{array}{l}\text { Mecanismos de } \\
\text { articulación } \\
\text { con el sistema }\end{array}$} & Eje de Coordinación Política & & & & \\
\hline & Eje de Coordinación Territorial & & & & \\
\hline & Eje de Apoyo Técnico & & & & \\
\hline & Eje de Vinculación Inter-institucional & & & & \\
\hline \multicolumn{6}{|c|}{\begin{tabular}{|l|l|} 
& No existe la estructura/instrumento/mecanismo o la función \\
\end{tabular}} \\
\hline & \multicolumn{5}{|c|}{$\begin{array}{l}\text { No existe la estructura/instrumento/mecanismo pero la carencia es suplida o bien existe la } \\
\text { estructura/instrumento/mecanismo, pero su utilidad es limitada }\end{array}$} \\
\hline & \multicolumn{5}{|c|}{ Existen la estructura/instrumento/mecanismo y la función } \\
\hline
\end{tabular}

Fuente: Elaboración propia en virtud del análisis realizado gracias a la información recopilada descrita anteriormente 
Figura 2: Tabla de Comparación de los Sistemas de Cooperación de Chile, España, Portugal e Ideal

\begin{tabular}{|c|c|c|c|c|c|}
\hline & Variables & Chile & España & Portugal & Ideal \\
\hline \multirow{5}{*}{$\begin{array}{l}\text { Sistema de } \\
\text { cooperación }\end{array}$} & Estructura Gerencial & & & & \\
\hline & Estructura de Adaptación & & & & \\
\hline & Estructura de Producción & & & & \\
\hline & Estructura de Mantenimiento & & & & \\
\hline & Estructuras de Apoyo & & & & \\
\hline \multirow{6}{*}{$\begin{array}{l}\text { Modalidades } \\
\text { de } \\
\text { cooperación }\end{array}$} & Cooperación Descentralizada en Organismos Gubernamentales & & & & \\
\hline & $\begin{array}{l}\text { Cooperación Descentralizada en Organismos Privados y de la Sociedad } \\
\text { Civil }\end{array}$ & & & & \\
\hline & Cooperación Triangular & & & & \\
\hline & Cooperación Bilateral & & & & \\
\hline & Cooperación Delegada & & & & \\
\hline & Cooperación transferida a organismos multilaterales & & & & \\
\hline \multirow{7}{*}{$\begin{array}{l}\text { Ámbitos de } \\
\text { acción }\end{array}$} & Ayuda Programática & & & & \\
\hline & Cooperación Financiera Reembolsable & & & & \\
\hline & Cooperación Técnica & & & & \\
\hline & Ayuda Humanitaria & & & & \\
\hline & $\begin{array}{l}\text { Formación de Capital Humano, Apoyo Científico, Apoyo al Desarrollo } \\
\text { Tecnológico }\end{array}$ & & & & \\
\hline & Fondos Especiales de Cooperación (Fiduciarios o Globales) & & & & \\
\hline & Educación para el desarrollo y sensibilización social & & & & \\
\hline \multirow{3}{*}{ Instrumentos } & Politica Exterior & & & & \\
\hline & Política de Cooperación/ Planes Rectores & & & & \\
\hline & Presupuesto & & & & \\
\hline \multicolumn{6}{|c|}{\begin{tabular}{l|l} 
No existe la estructura/instrumento/modalidad/ámbito \\
\end{tabular}} \\
\hline & \multicolumn{5}{|c|}{$\begin{array}{l}\text { No existe la estructura/instrumento/modalidad/ámbito pero la carencia es suplida o bien existe la } \\
\text { estructura/instrumento/modalidad/ámbito, pero su utilidad es limitada. }\end{array}$} \\
\hline & \multicolumn{5}{|l|}{ Existe la estructura/instrumento/modalidad/ámbito } \\
\hline
\end{tabular}

Fuente: Elaboración propia en virtud del análisis realizado gracias a la información recopilada descrita anteriormente 
tructuras que permitan la vinculación, sin embargo el eje de articulación territorial es desarrollado por las embajadas dependientes del Ministerio de Relaciones Exteriores, por lo que la función queda supeditada a una gestión más de estilo networking. Sin embargo, cabe mencionar que esta es una condición existente en todas las demás agencias de cooperación internacional de Latinoamérica y posiblemente haya lineamientos estratégicos y de gestión que determinen que esto se desarrolle así. Adicionalmente, el eje de articulación inter-institucional es particularmente débil en AGCI, esto pues, si bien existe la estructura encargada de desarrollar esta labor (Departamento de Coordinación), esta es eficiente exclusivamente en la gestión de acuerdos que busquen resolver las necesidades directas de AGCI (capturar insumos para la producción), pero no para capturar demandas de las demás instituciones del sistema a raíz de posibles acuerdos de cooperación desarrollados de forma ajena a la Agencia. Por su parte, los otros dos casos estudiados, mantienen estructuras que permiten una gestión exitosa de los distintos ejes de coordinación.

\section{Análisis de estructura, modalidades, ámbitos de acción e instrumentos del sistema}

La estructura del sistema chileno de cooperación cumple con las cinco estructuras ${ }^{7}$. No obstante, la de Apoyo pareciera tener un área de acción limitada o bien es incapaz de cumplir con su rol a cabalidad, esto se explica por las debilidades existentes en el eje de vinculación inter-institucional y en la estructura encargada de administrar dicho vinculo.

En cuanto a los otros dos sistemas comparados, en ellos se identifican claramente la existencia de las estructuras descritas.

Por otra parte, respecto a las modalidades de cooperación, el sistema nacional desarrolla, principalmente, cooperación descentralizada en organismos gubernamentales, cooperación triangular y cooperación bilateral. Adicionalmente, el sistema ejecuta, de forma limitada, la cooperación descentralizada en organismos privados y de la sociedad civil. Por último, la cooperación es transferida a organismos multilaterales, la que es desarrollada por algunos órganos del Estado. En contraposición, los otros dos sistemas utilizan todas las modalidades descritas.

En lo relativo a los ámbitos de acción, el sistema nacional actúa en 3 de los 7 descritos: Cooperación Técnica, Formación de Capital Humano y

\footnotetext{
${ }^{7}$ Estructura Gerencial, Estructura de Adaptación, Estructura de Producción, Estructura de Mantención y Estructura de Apoyo.
}

Fondos Especiales de Cooperación. Por otra parte, los ámbitos que el sistema chileno de cooperación no desarrolla son Ayuda Programática, Cooperación Financiera Reembolsable, Ayuda Humanitaria (o más bien se desarrolla de forma ajena al sistema de cooperación) y Educación para el Desarrollo, la que parece depender del nivel de consolidación a nivel nacional del Sistema de Cooperación Internacional. En este caso particular, la carencia de los tres primeros Ámbitos de Acción ausentes, parece explicarse, al menos en una parte, por definiciones estratégicas más que por la presencia de nodos críticos, pues, tal como expone, por una parte, Ma. Cristina Lazo (2015), la ayuda humanitaria es (o puede ser entendida) como un instrumento que "va por otro carril" y, por otra parte, Eugenio Pérez (2015), es el Ministerio de Relaciones Exteriores el que actua puntualmente respecto de requerimiento s recibidos desde el exterior y depende de decisiones políticas el alojamiento del rol.

Finalmente, en lo que respecta a los instrumentos del sistema, Chile recientemente formalizó su primera Política de Cooperación Internacional para el Desarrollo, , la cual enmarca su nueva Estrategia de Cooperación Internacional para el Desarrollo 2015-2018, por lo que el país utiliza los tres instrumentos.

Respecto a España y Portugal, ambos utilizan todos los instrumentos definidos.

\section{Análisis de los resultados de la encues- ta. Dimensión Instrumental}

Con respecto a la dimensión de instrumentos, se plantearon las siguientes afirmaciones: Afirmación 1: Existe una estrategia clara que de lineamientos para la gestión en su departamento. Afirmación 2: Los procesos de su departamento tienen métricas claras y eficientes que permitan medir y evaluar su actividad y desempeño. Afirmación 3: En su departamento existen instrumentos claros de planificación que se alineen con los objetivos estratégicos institucionales. Afirmación 6: Los instrumentos de formulación de proyectos son pertinentes, eficientes y, por tanto, dan respuesta a las necesidades del sistema nacional de cooperación. Afirmación 7: Existe una visión clara sobre las principales estrategias futuras y la realidad actual de la organización. Afirmación 8: Existe claridad respecto del "modelo de negocio" y estrategia actual de la institución. Afirmación 9: Los instrumentos de planificación territorial o geográfica son suficientes y eficientes y, por tanto, dan respuesta a las necesidades del sistema nacional de cooperación. Afirmación 10: Los instrumentos de planificación a nivel presupuestarios son 
suficientes y eficientes y, por tanto, dan respuesta a las necesidades del sistema nacional de cooperación. Afirmación 11: El presupuesto institucional es suficiente para el adecuado desarrollo de sus funciones. Afirmación 22: Las estrategias y servicios institucionales son consistentes con las políticas públicas subyacentes (política exterior y de desarrollo nacional).

Respecto a los niveles de estudio, las primeras tres afirmaciones corresponden a un análisis a nivel departamental; las siguientes 6 , corresponden al análisis institucional del órgano rector y, por último, la afirmación 22 corresponde al nivel del sistema.

Respecto a los resultados, es posible mencionar que en el primer nivel existe una clara dispersión en la evaluación de los instrumentos, particularmente respecto a las afirmaciones 1 y 3, presentando ésta última posturas particularmente extremas; por su parte, la afirmación 2 parece presentar posturas más homogéneas tendientes a la disconformidad respecto a la eficiencia de las métricas, lo cual tiene particular sentido si se considera que la elaboración de estas se coordina centralizadamente.

El grado de dispersión en las respuestas mostrado puede explicarse por las diferencias existentes en cada división respecto a la formulación y uso de este tipo de instrumentos, los cuales son manejados de forma (aparentemente) heterogénea, generando desigualdad en la gestión institucional.

Respecto al nivel institucional, si bien el panorama no cambia demasiado, existiendo tendencias hacia el centro, los datos no presentan dispersiones ni distribuciones tan marcadas hacia ambos extremos simultáneamente, salvo por la afirmación 6. Esto puede interpretarse como falta de claridad respecto a las necesidades del sistema nacional de cooperación sobre los instrumentos de formulación de proyectos.

Por otra parte, respecto al resto de las afirmaciones de esta dimensión, las preferencias son un poco más claras, como se ve en los casos de las afirmaciones 9,10 y 11, sobre las cuales se demuestra una tendencia hacia el desacuerdo. Esto puede interpretarse como deficiencias institucionales en estos temas. A la inversa, la afirmación 7, muestra una tendencia hacia el acuerdo. Por último, la afirmación 8 , si bien hay una distribución en las respuestas que va hacia ambos sentidos, existe, igualmente, una marcada tendencia hacia el centro.

Por último, a nivel de sistema, la tendencia respecto a la alineación de las estrategias y servicios institucionales se muestra entre el "ni acuerdo ni desacuerdo" y el "acuerdo.

\section{Dimensión Estructural}

Respecto al a dimensión estructural, se plantearon las siguientes afirmaciones: Afirmación 4: La estructura de su Departamento es suficiente, permite una gestión eficiente. Afirmación 16: La organización posee divisiones encargadas de facilitar los procesos de adaptación y evolución del sistema de cooperación a las nuevas necesidades. Afirmación 17: Los procesos sustantivos de la institución (del giro del negocio) tienen dueños claros y conocidos al interior de la organización. Afirmación 18: Los procesos de soporte legal tienen dueños claros y conocidos al interior de la organización. Afirmación 19: Los procesos de soporte administrativo y presupuestal tienen dueños claros y conocidos al interior de la organización. Afirmación 20: Existe una estructura de control operacional útil para el análisis y evaluación de los procesos al interior de la organización. Afirmación 21: El marco normativo y reglamentario de la institución es adecuado para el desempeño de sus labores.

En lo relativo a los niveles de estudio, la primera afirmación responde al nivel departamental y las siguientes 6 corresponden al nivel institucional del órgano rector.

Respecto a los resultados, la figura 6 muestra la evaluación de los funcionarios encuestados sobre la adecuación de la estructura de sus departamentos para el desempeño de sus labores. En este sentido, es posible evidenciar que los departamentos de CTPD y Cooperación Bimultilateral son los mejor evaluados, lo cual tiene sentido si se considera que son los únicos departamentos de línea que no se encuentra subdivididos en unidades de "facto".

Ahora bien, a pesar de lo anterior, la evaluación a nivel general de todos los departamentos parece estar más cercana a lo "regular".

Por otra parte, respecto a las afirmaciones de nivel institucional, la afirmación 16 hace referencia a la estructura institucional y su capacidad para facilitar la adaptación y evolución de la organización, respecto de la cual hay gran discrepancia, según evidencia el nivel de dispersión de las respuestas mostrado en la figura 7. Una posible explicación para este fenómeno es que, dado que no existe una unidad o división encomendada específicamente esta labor, son las figuras ad-hoc y los altos rangos jerárquicos los encargados de definir los planes de adaptación (Jefes de Departamento y Comité Directivo), por lo que las experiencias individuales y colectivas de los funcionarios (a nivel departamental) son las que determinan su evaluación.

En lo referido al dominio de los procesos sustanti- 
Figura 3: Distribución de evaluación de afirmaciones sobre instrumentos a nivel departamental

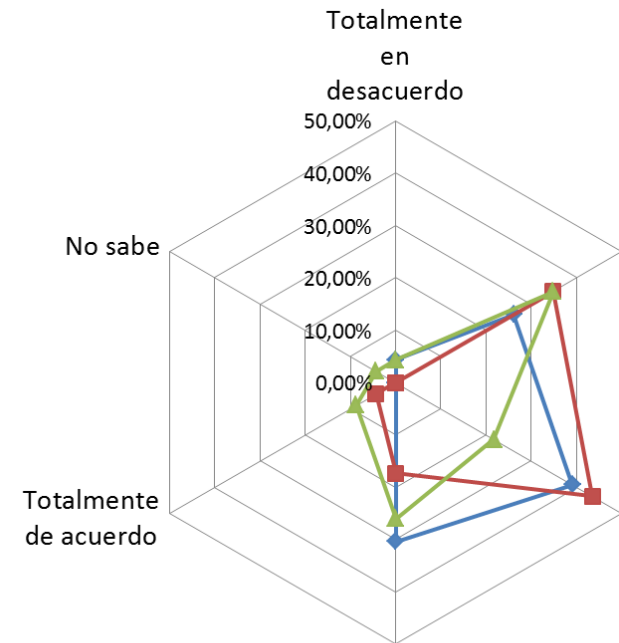

De acuerdo

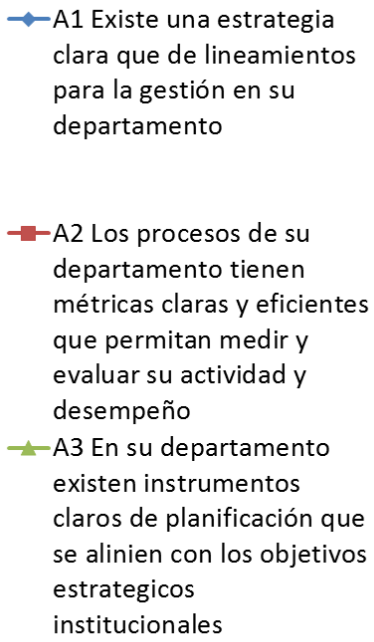

Fuente: laboración propia en base a datos recolectados mediante encuesta

Figura 4: Evaluación sobre instrumentos de planificación y estrategia a nivel institucional

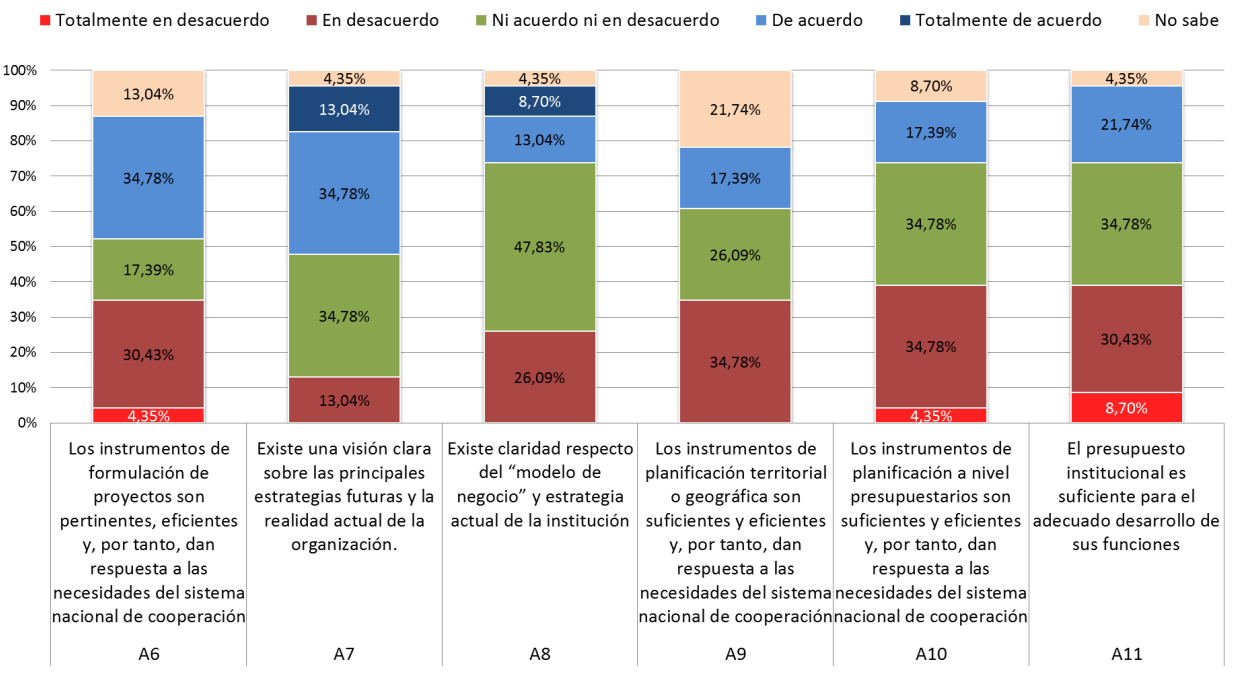

Fuente: Elaboración propia en base a datos recolectados mediante encuesta 
Figura 5: Distribución de evaluación de afirmaciones sobre instrumentos a nivel sistémico

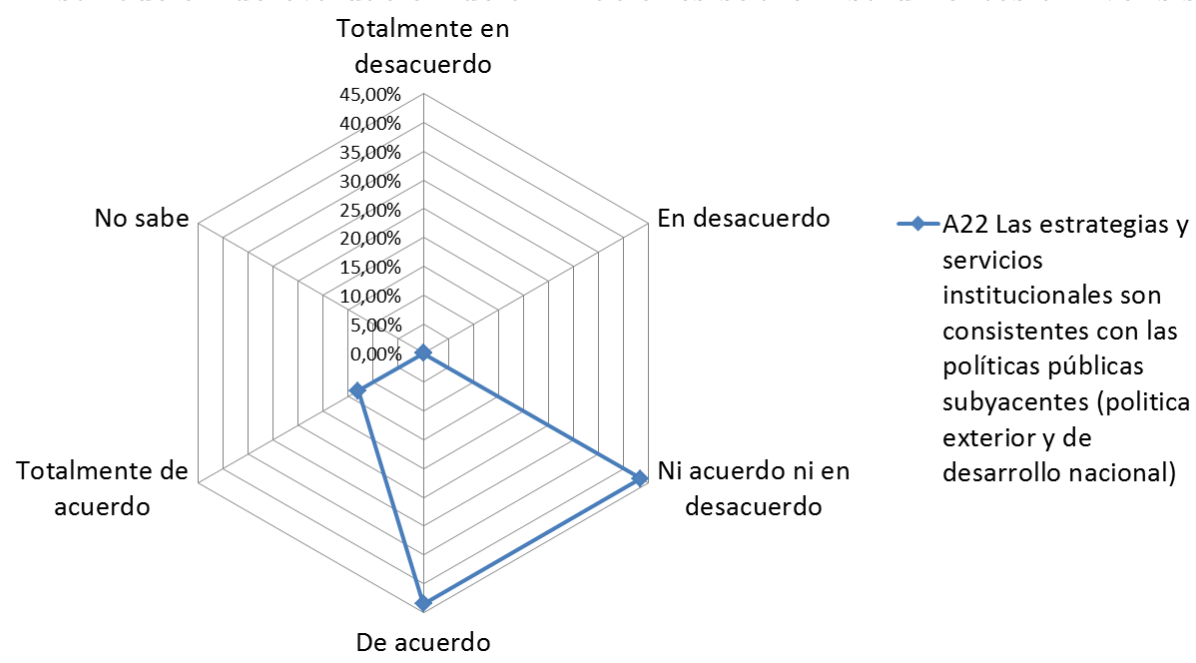

Fuente: Elaboración propia en base a datos recolectados mediante encuesta

Figura 6: Evaluación de las estructuras departamentales Afirmacion 4: La estructura de su Departamento es suficiente, permite

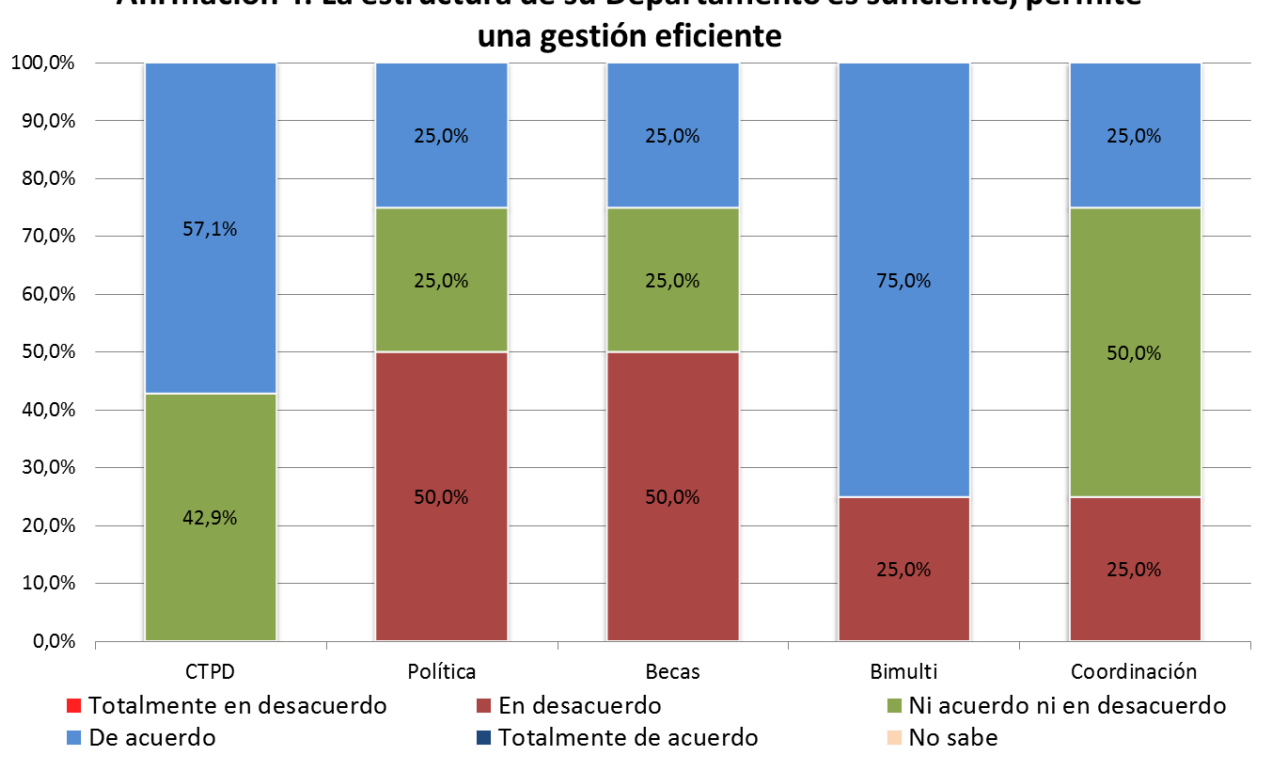

Fuente: Elaboración propia en base a datos recolectados mediante encuesta 


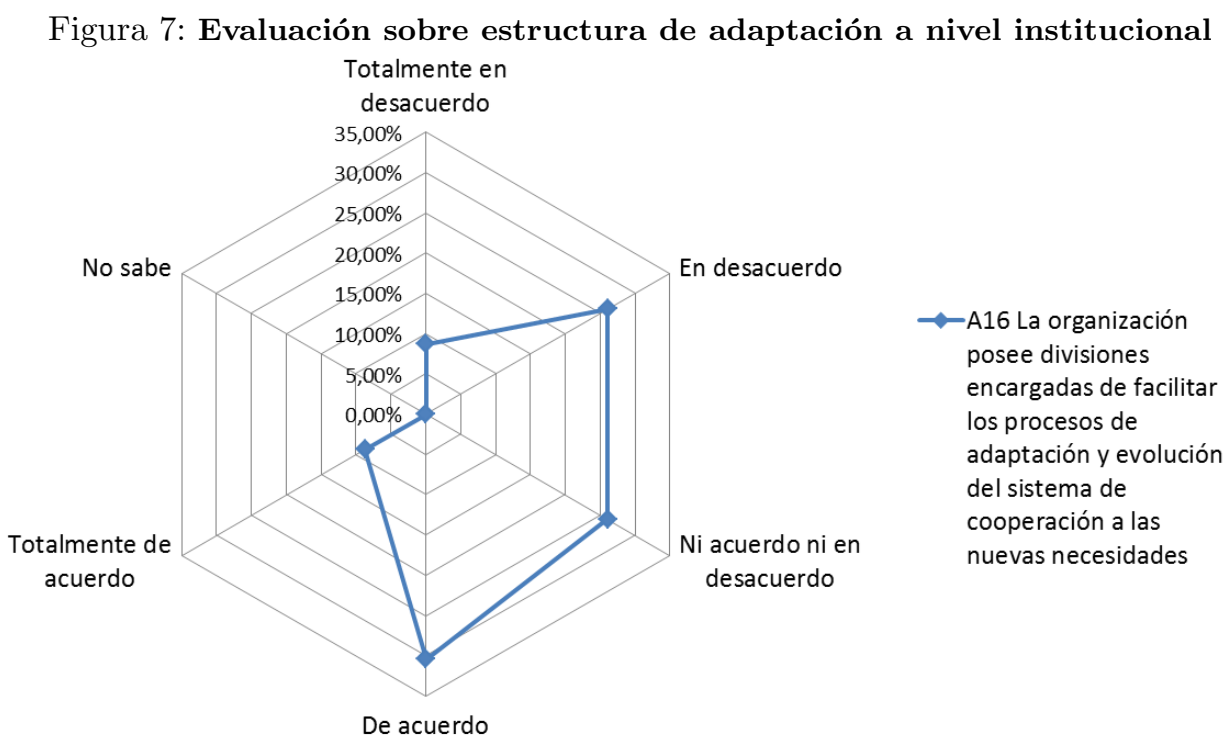

Fuente: Elaboración propia en base a datos recolectados mediante encuesta

vos y de soporte institucional, existe cierta claridad sobre este punto, pues la mayoría de los funcionarios encuestados declararon estar de acuerdo con las afirmaciones planteadas. Ahora bien, aunque la evaluación es mayormente positiva, en el caso de los procesos sustantivos, hay menos aceptación de la afirmación, respecto a los otros tipos de procesos, por lo que, en comparación, los procesos sustantivos parecen estar más diluidos al interior de la estructura organizacional.

Respecto a la afirmación 20, existencia de estructuras de control operacional para el análisis y evaluación de procesos al interior de la organización y su utilidad para la institución, según muestra la figura 8 , existe cierta tendencia hacia el desacuerdo con la afirmación. Esto se puede interpretar como la existencia de un nodo crítico de gestión en esta materia, pues la función existe y es desarrollada por los departamentos y unidades pertenecientes a la tecnoestructura (Auditoría Interna, el Departamento de Coordinación, el área de Planificación y el área de Control de Gestión). En consecuencia, un posible diagnóstico para este nodo crítico es la existencia de estancos en los flujos de información y gestión al interior de la organización que impiden el adecuado y eficiente desarrollo de labores de dichas áreas.

Finalmente, respecto a la afirmación 21, relacionada con el marco normativo institucional y su adecuación para el desempeño de la Agencia, la figura 9 muestra evidencia de la irregularidad en la evaluación de este punto. Esto puede explicarse porque, si bien el marco regulatorio actual permite el desempeño de las labores cotidianas de la Agencia, buena parte de este, específicamente el que se refiere al desempeño de las labores de línea institucional, no se ha actualizado desde el año $2004^{8}$. De esta manera, ciertas funciones no se encuentran del todo reguladas, quedando fuera elementos como la función de agente coordinador a nivel nacional de la cooperación (más allá de lo declarativo), así mismo tampoco incorpora funciones más propias de la cooperación "moderna", como las relativas al monitoreo y evaluación de los programas de cooperación.

\section{Dimensión de articulación y vinculación del sistema}

Respecto a la articulación y vinculación del sistema, se plantearon las siguientes afirmaciones: Afirmación 5: En su departamento existen mecanismos definidos para vincularse con sus clientes (tanto internos como externos). Afirmación 12: No existen "insularidades", es decir, las diferentes áreas internas cooperan y se coordinan. Afirmación 13: La gestión institucional de la cooperación descentralizada es eficiente y suficiente (entiendas por descentralizada toda la que no es desarrollada directamente por AGCI). Afirmación 14: La estructura organizacional permite una adecuada vinculación vertical que permita alinear los planes de coopeación con las demás políticas públicas relacionadas (política exterior, programa de gobierno). Afirmación 15: La institución posee estructuras capaces de administrar adecuadamente los nexos bidireccionales con los stakeholders (tanto para capturar insumos como para atender demandas). Afirmación 23: Existe un análisis permanente de su mapa de stakeholders.

\footnotetext{
${ }^{8}$ Salvo el reglamento que fija la estructura jerárquica de la Agencia, el que se acaba de modificar, pero que, en opinión
} del autor, aún es insuficiente. 
Figura 8: Evaluación sobre la estructura y gestión del control operacional y evolución de proceso al interior de la institución

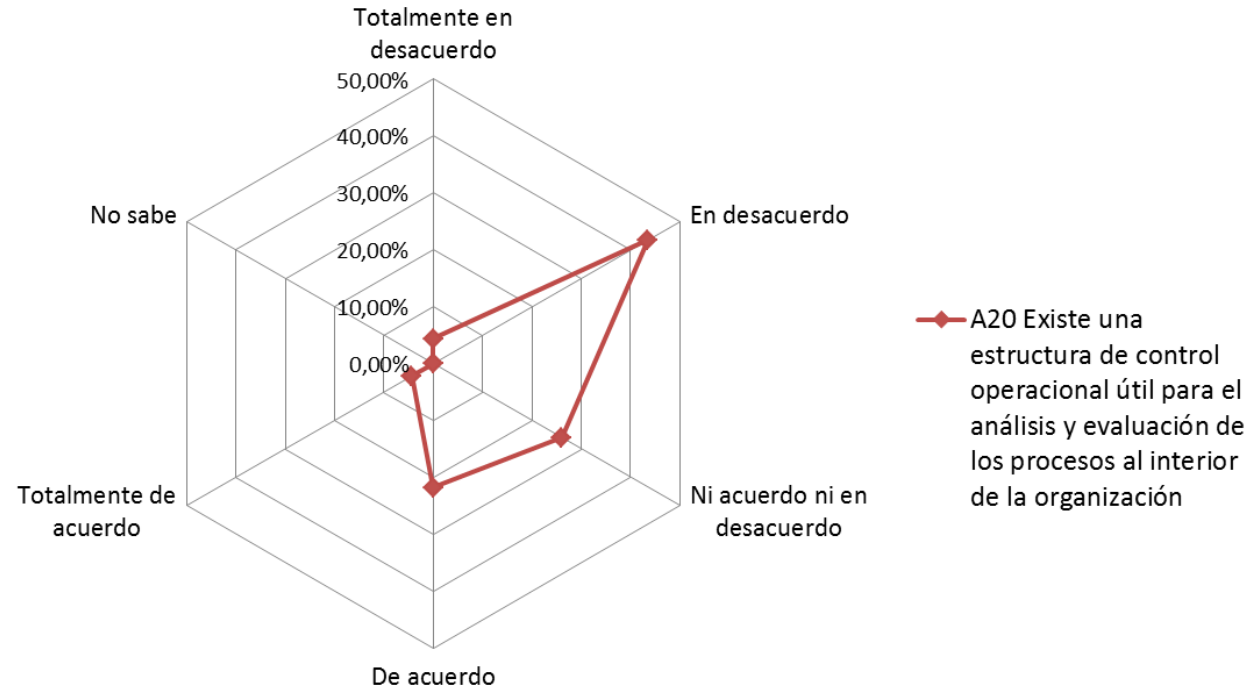

Fuente: Elaboración propia en base a datos recolectados mediante encuesta

Figura 9: Evaluación sobre la utilidad del marco normativo y reglamentario institucional

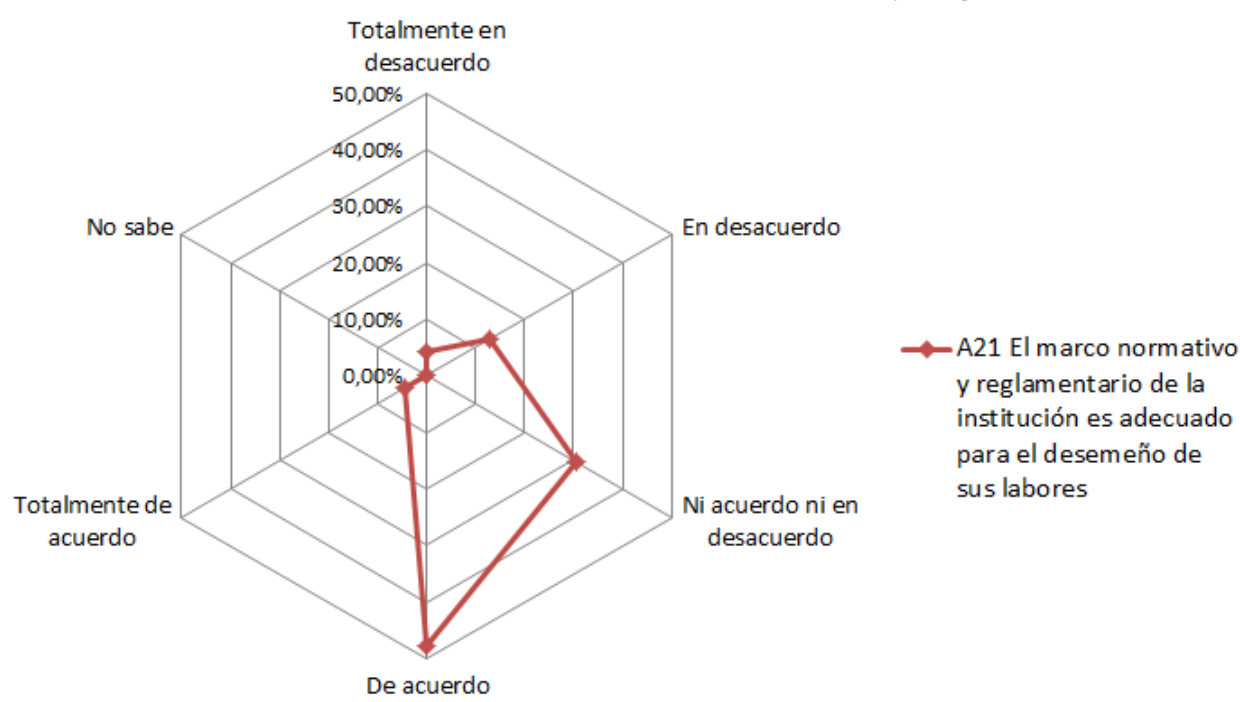

Fuente: Elaboración propia en base a datos recolectados mediante encuesta 
Afirmación 24: La agencia es capaz de gestionar adecuadamente las relaciones con sus stakeholders. Afirmación 25: Las unidades territoriales (embajadas) están suficientes coordinadas con AGCI para el desarrollo de proyectos de cooperación.

Respecto a las áreas de estudio, la primera afirmación responde al nivel departamental, las siguientes 4 corresponden al nivel institucional del órgano rector y las últimas 3 hacen referencia a la vinculación del sistema.

Sobre los resultados, a nivel departamental es posible evidenciar que buena parte de los encuestados denuncia la inexistencia o ineficiencia de los mecanismos de articulación, por lo que es posible hablar ya de insularidades al interior de la Agencia.

Una posible explicación para el nivel de dispersión en los datos de esta figura, es que la percepción de "insularidad" que vive cada funcionario está determinada por la experiencia individual, la cual puede variar dependiendo de sus esfuerzos y capacidades propias. Evidencia de esto último, es el análisis que se puede realizar sobre la misma afirmación, pero esta vez a nivel organizacional o institucional.

En concordancia con lo anterior, es posible concluir que existen deficiencias a nivel de gestión operativa en los vínculos interdepartamentales de la Agencia.

Continuando con el análisis, respecto a la afirmación 13 sobre la gestión de la cooperación descentralizada, ka figura 12 muestra una clara tendencia al desacuerdo. La mayoría de los encuestados declara que la gestión que realizada por AGCI respecto a la cooperación, no es desarrollada directamente por la Agencia no es ni suficiente ni evidente. Esto deja ver la existencia de un nodo critico de gestión sobre la coordinación de esta materia.

Por otra parte, las afirmaciones 14 y 15 tratan respecto los vínculos verticales y horizontales del órgano rector con sus stakeholders. La figura 11 muestra que, para la afirmación 14, la tendencia parece ir débilmente al acuerdo, lo que puede indicar que dicho vinculo, si bien existe, no está del todo desarrollado, o bien que el mismo no es tan evidente para todos los funcionarios de la institución. Por su lado, respecto a la afirmación 15, la tendencia hacia la evaluación regular-positiva es mucho más evidente, por lo que es posible afirmar que, al menos en este aspecto, la relación con los demás servicios y organismos interesados es fluida, pero solo en aquellos casos en los que AGCI tiene injerencia directa.

La figura 14 muestra la percepción de los encuestados respecto a la capacidad de administración de la agencia sobre las relaciones con los stakeholders del sistema de cooperación. Se observa que, dadas las diferencias obtenidas entre las afirmaciones 23 y 24 , si bien la agencia posee una capacidad razonable de gestión, no es capaz de realizar una análisis permanente del mapa de los mismos.

Por último, respecto a la afirmación 25 sobre la coordinación con las unidades territoriales (embajadas), la figura 15 muestra que la evaluación sobre este punto es regular-buena. Esto podría indicar que, si bien parecen haber tensiones entre la gestión de AGCI y la de las embajadas unidades territoriales para el desarrollo de proyectos de cooperación, la coordinación es, al menos, funcional. En este sentido, a pesar de las dificultades existentes, hay argumentos para sostener este mecanismo de operación. Por una parte, significa ahorro de recursos para la Agencia, y por otra, permite fortalecer el vínculo entre política de cooperación y política exterior.

\section{Modalidades de Cooperación}

Respecto al análisis sobre las modalidades de cooperación ejecutadas, se plantearon las siguientes afirmaciones: Afirmación 26: Existen lineamientos claros que permiten definir cuales mecanismos de cooperación son prioritarias para el sistema nacional. Afirmación 27: La gestión de la cooperación bilateral es eficiente y suficiente. Afirmación 28: La gestión de la cooperación multilateral es suficiente y eficiente. Afirmación 29: La gestión de la cooperación triangular es eficiente y suficiente.

Respecto a la afirmación 26, la tendencia es hacia el desacuerdo, lo cual puede tener dos interpretaciones. Por una parte, una interpretación es que los lineamientos no existen y, por lo tanto, las modalidades se priorizan en la medida en que aparecen oportunidades. Por otra parte, se puede interpretar que los lineamientos sí existan, pero estos no se encuentren suficientemente formalizados y difundidos en el sistema (y al interior de la Agencia). Frente a las alternativas presentadas, es posible inclinarse a la última opción si se tiene en cuenta que el porcentaje de funcionarios "de acuerdo" con la afirmación no es menor, además que el porcentaje de funcionarios que declaró no estar "ni de acuerdo ni en desacuerdo" con la afirmación fue de un 30,4\%, lo que también puede interpretarse como la existencia de lineamientos insuficientes o poco claros.

Por último, respecto a la eficiencia y suficiencia de la cooperación bilateral, multilateral y triangular, los resultados expuestos por la figura 16 muestran que, si bien es posible afirmar que la cooperación triangular gestionada (y ofrecida) por el siste- 
Figura 10: Evaluación de los mecanismos de vinculación interdepartamental

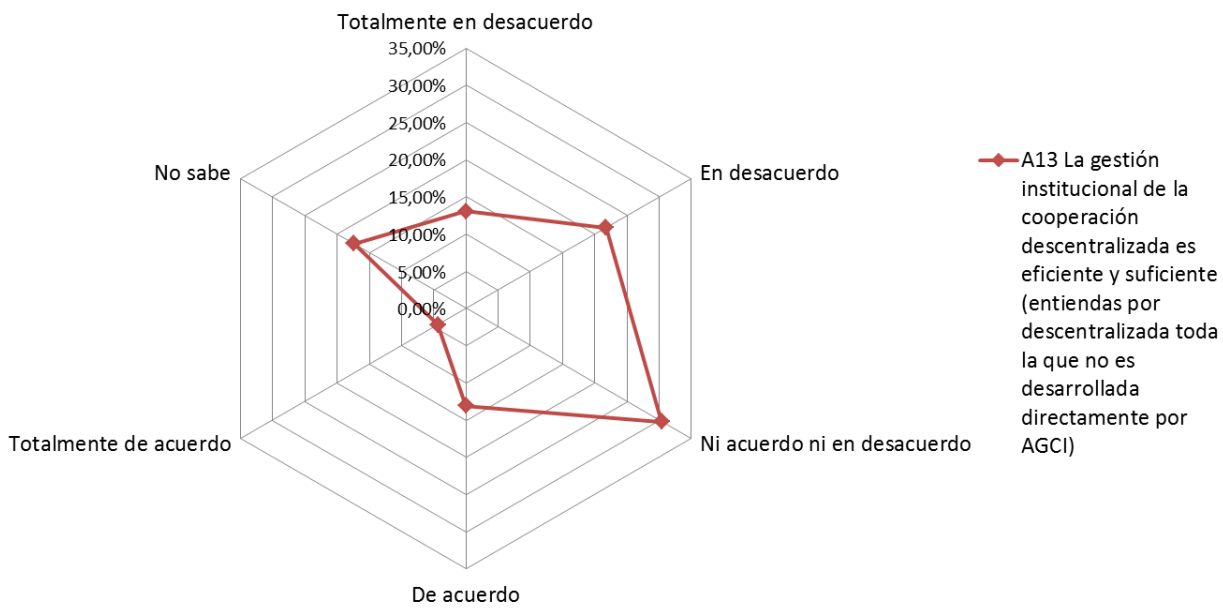

Fuente: Elaboración propia en base a datos recolectados mediante encuesta

Figura 11: Evaluación sobre el nivel de insularidad a nivel institucional Totalmente en

desacuerdo

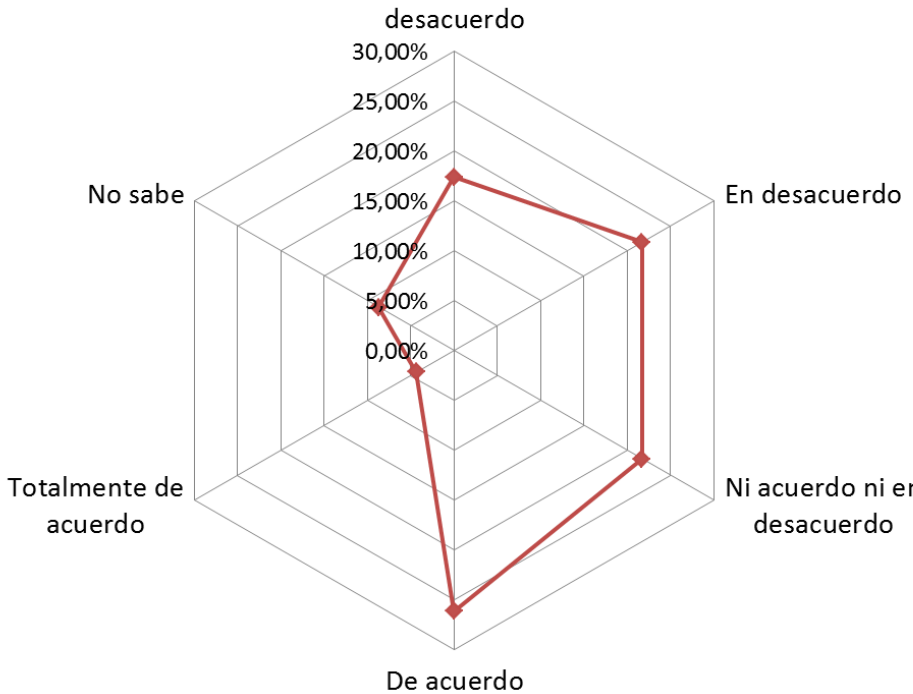

$\rightarrow$ A12 No existen

"insularidades",

es decir, las

diferentes áreas

internas

cooperan y se

coordinan.

Fuente: Elaboración propia en base a datos recolectados mediante encuesta 
Figura 12: Gestión de la cooperación descentralizada a nivel institucional

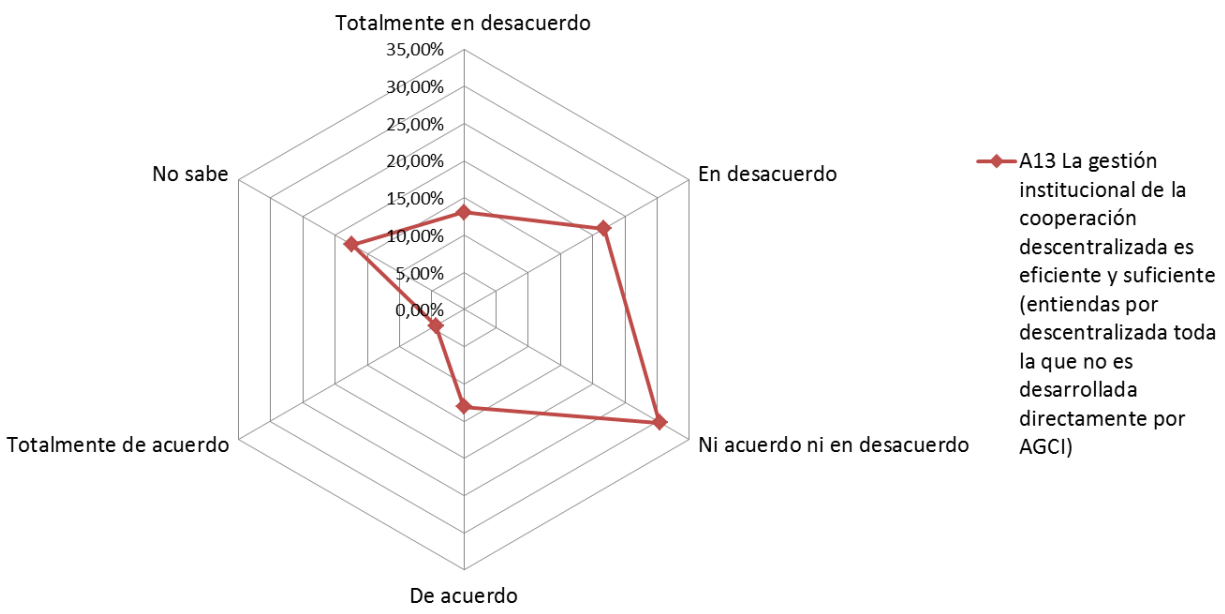

Fuente: Elaboración propia en base a datos recolectados mediante encuesta

Figura 13: Capacidad estructural para la gestión de vínculos y nexos con los stakeholders a nivel institucional

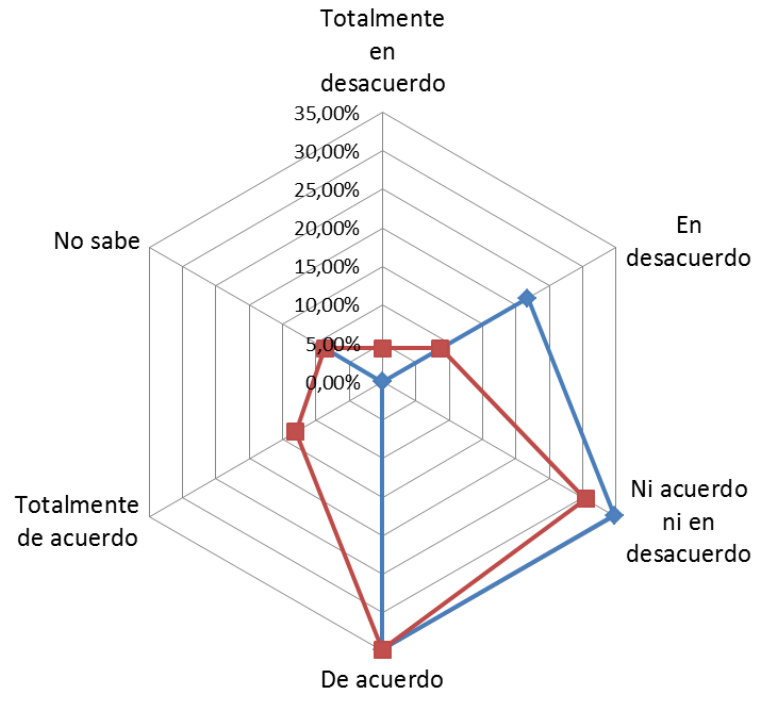

Elaboración propia en base a datos recolectados mediante encuesta

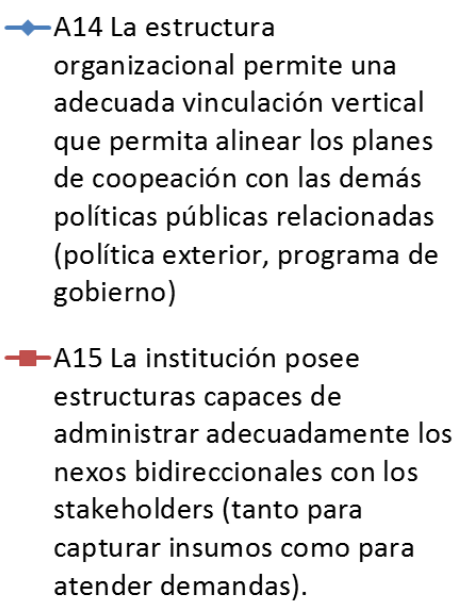

Fuente:

Figura 14: Gestión de stakeholders a nivel sistémico

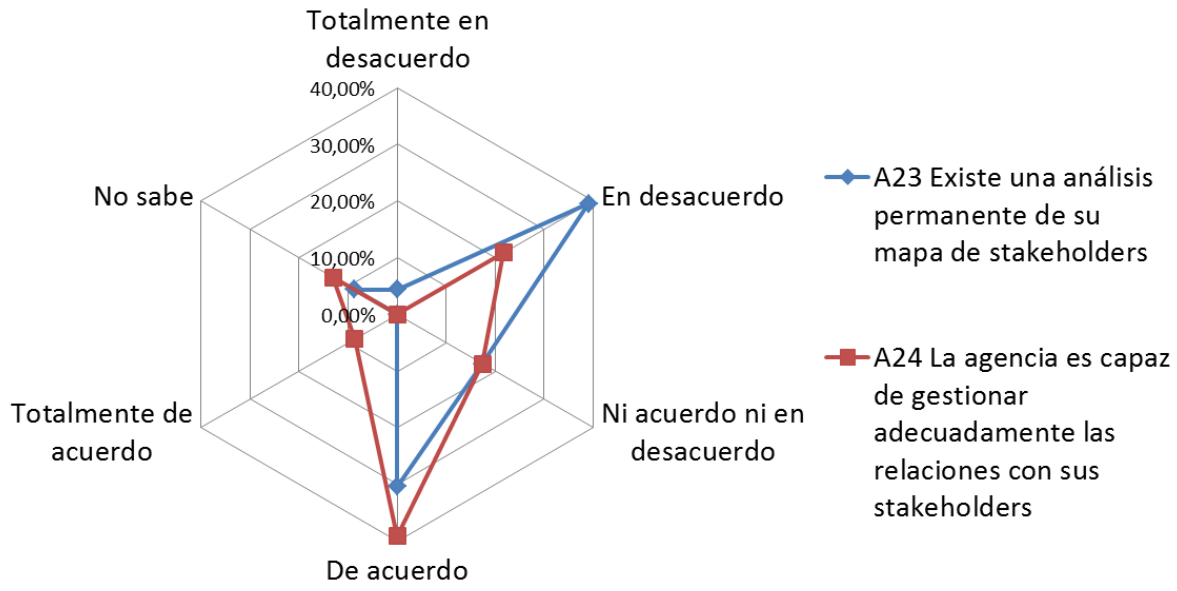

Fuente: Elaboración propia en base a datos recolectados mediante encuesta. 
Figura 15: Coordinación del órgano rector con embajadas

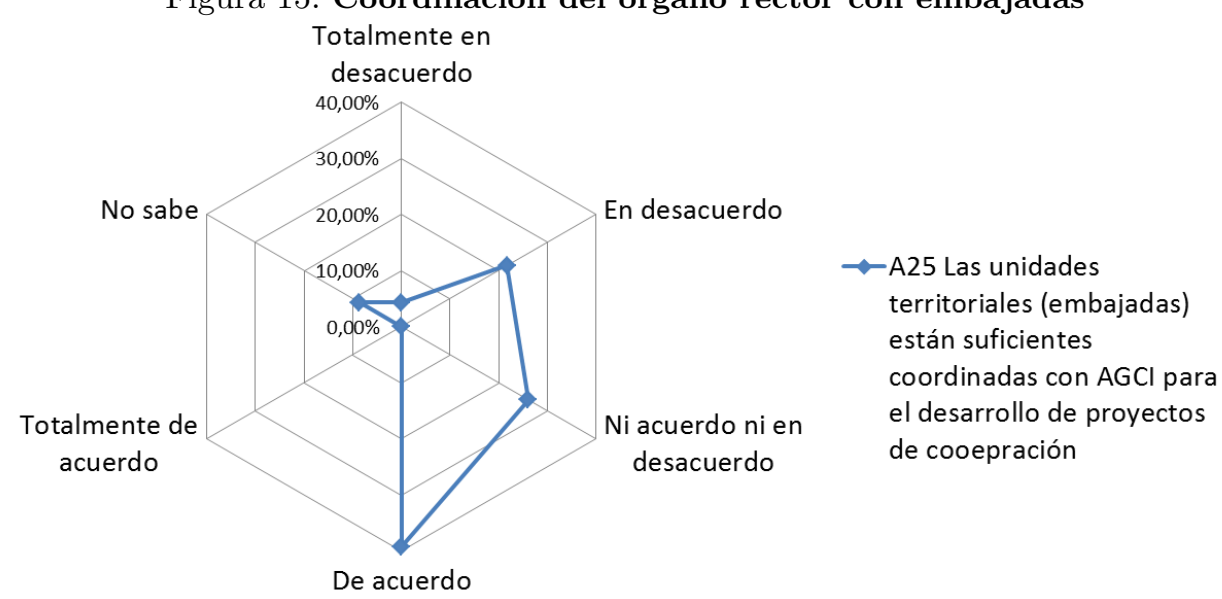

Fuente: Elaboración propia en base a datos recolectados mediante encuesta

ma y coordinada por AGCI es suficiente y eficiente, dadas las capacidades de la Agencia y la demanda existente; lo mismo no ocurre con la cooperación bilateral y mucho menos con la multilateral, pues sus evaluaciones se encuentran más cerca de lo "regular" e incluso lo "negativo". Otro dato importante a destacar, es el alto porcentaje de encuestados que respondieron con la opción "no sabe" respecto a las afirmaciones 28 y 29 , considerando que todos son profesionales y funcionarios de los departamentos de línea (que gestionan la cooperación), lo cual reafirma la noción de existencia de nodos críticos referidos a la gestión de información (datos y métricas sobre cooperación) y de estrategia (definición y difusión de la estrategia institucional).

\section{Conclusiones}

El sistema de cooperación de Chile presenta nodos críticos tanto a nivel estructural, como de gestión, los cuales dificultan el desarrollo eficiente y efectivo de las funciones pertinentes a la cooperación para al desarrollo y el apoyo a la política exterior.

\section{Nodo Critico: Coordinación Inter- institucional}

Uno de los principales nodos críticos identificados es el relacionado con los vínculos intersectoriales. En términos concretos, este nodo dice relación con la incapacidad del órgano rector para intervenir en los canales de comunicación y producción de las demás partes del sistema de cooperación, entendiendo por intervención, la participación directa en la entrega de cooperación institucional o al menos el monitoreo de este proceso.

En general, tal como se mencionó, los distintos organismos de Estado pueden gestionar cooperación de forma autónoma. Un caso particular de esta modalidad es el del Fondo de Solidaridad e Inversión Social (FOSIS), organismo que, si bien participa activamente de la gestión de cooperación desarrollada por AGCI, también ha manejado su propia agenda durante los últimos años. En este sentido, como menciona Claudio Prim (2015), el Fondo participa tanto en mesas técnicas de diálogo internacional (bilateral o multilateral), como en la organización de eventos con instituciones contrapartes de otros países, llegando incluso, a desarrollar proyectos de cooperación independientemente, con apoyo de instituciones extranjeras como la GIZ de Alemania o la OEA. De esta manera, adquieren particular relevancia las redes personales creadas entre profesionales, lo cual, en alguna medida, evidencia la debilidad de reglas formales para la configuración de proyectos de cooperación internacional.

Pareciera ser que este nodo crítico se asienta en la limitada capacidad institucional del órgano rector de capturar los insumos o demandas de cooperación que se originan en los espacios de participación de los demás órganos del sistema (sectores nacionales). Dicho nodo, que parece obedecer a debilidades tanto estructurales como de gestión, puede explicarse por varias razones: la debilidad institucional formal para la articulación de la cooperación mencionada precedentemente. Esto es entendible si se considera que AGCI no ha sufrido reformas estructurales o normativas desde que cambio su rol hacia la entrega de cooperación horizontal técnica, incluyendo la desarticulación, hasta recientemente, del área encargada de la coordinación sectorial, tal como explica María Cristina Lazo (2015) por lo que se requiere el fortalecimiento institucional de dicha 
Figura 16: Evaluación sobre gestión de las modalidades de cooperación a nivel sistémico

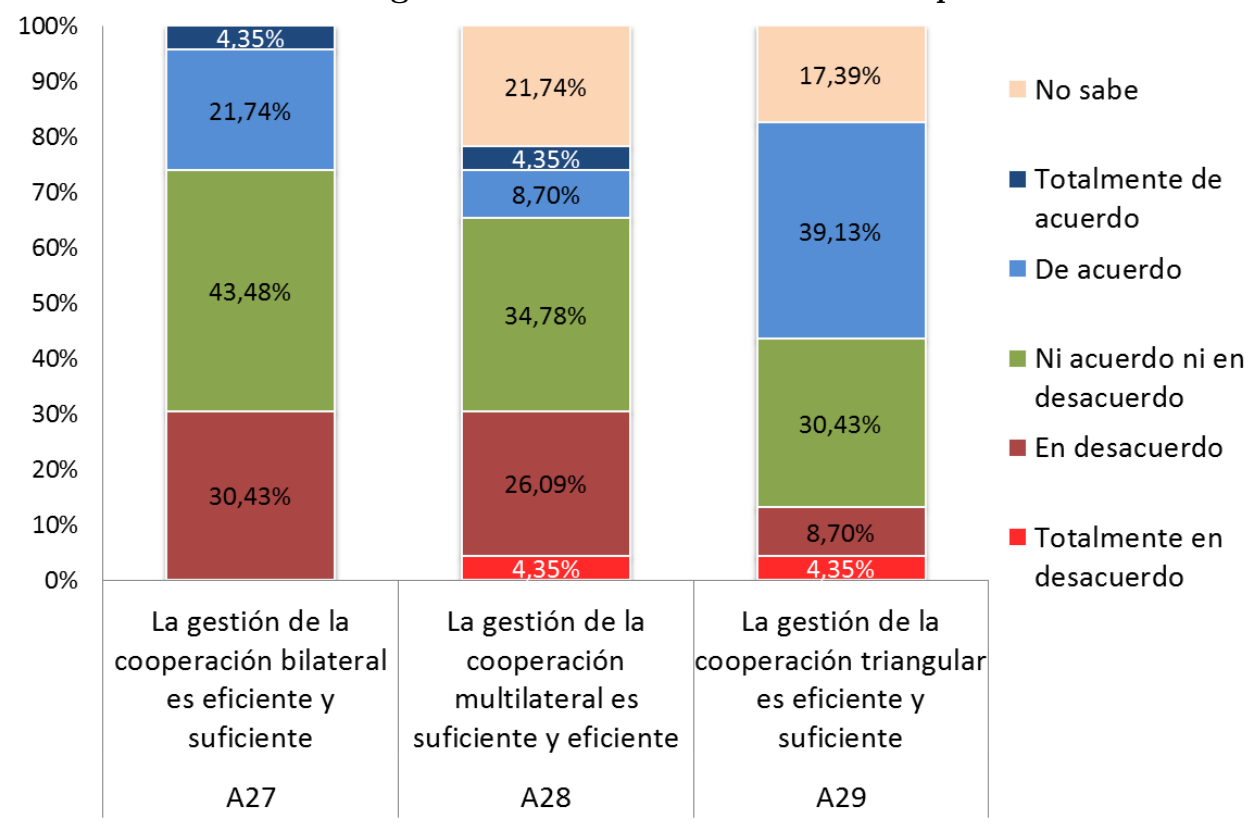

Fuente: Elaboración propia en base a datos recolectados mediante encuesta

área.

\section{Definiciones Estratégicas}

En términos de planificación estratégica, la Agencia de Cooperación Internacional de Chile, recientemente formalizó su primera Política de Cooperación Internacional de Chile para el Desarrollo y Estrategia de Cooperación Internacional para el Desarrollo 2015-2018, ambas elaboradas por un comité interdisciplinario de expertos del área de la cooperación internacional, con el apoyo de las agencias de Brasil, Argentina, México y especialmente de España.

Respecto, a la Política de Cooperación, ésta fue definida con un horizonte de 15 años (2015-2030) que reconoce su integración con la política exterior, alejándose, tal como menciona Eugenio Pérez (2015) en la entrevista, de la concepción original de la cooperación como instrumento de la primera; y que opera la formalización de la visión de largo plazo de lo que debe ser la gestión nacional de la cooperación internacional, para lo cual, ofrece un diagnóstico en términos de contexto y desafíos, y presenta los siguientes fundamentos orientadores de la cooperación internacional gestionada por el país:

- Fortalecimiento de la Democracia y sus instituciones

- Promoción de la Paz, la Convivencia y la Seguridad Humana
- Compromiso con la integración y la convergencia regional en América Latina y el Caribe

- Fortalecimiento del rol de América Latina y el Caribe en la gobernanza mundial.

- Promoción de la dignidad de las personas, el desarrollo inclusivo y sostenible desde un enfoque de derechos.

Ahora bien, la política, como tal permite, definir los pilares que sostienen la cooperación chilena, no obstante, salvo por el "Compromiso con la integración y la convergencia regional en América Latina y el Caribe", dichas orientaciones parecieran ser tan amplias que, más que una guía, se configuran como un compromiso con el respeto al estado de derecho y a la gobernanza global.

Por su parte, respecto a la Estrategia de Cooperación Internacional de Chile para el Desarrollo 2015-2018, ésta se define en un horizonte de mediano plazo establece 5 criterios orientadores:

1. Concentración de programas y proyectos en América Latina y el Caribe con estrategias diferenciadas,

2. Eficiencia mediante acciones flexibles y replicables,

3. Responsabilidad mutua y articulación de estrategias,

4. Gestión basada en la participación, el aprendizaje y el intercambio de conocimientos, y 
5. Fortalecimiento de las capacidades de la Agencia

Los cuales "siguen los fundamentos de la cooperación chilena, se trazan para el mediano plazo y dan lugar a los objetivos estratégicos, las líneas de acción concretas" (AGCI, 2016), por lo que parecieran ser una mezcla entre la expresión de los principios de cooperación internacional aplicada al sistema nacional y los desafíos que se identifican para la AGCI.

La Estrategia establece, también, 3 objetivos estratégicos:

1. Avanzar hacia un desarrollo inclusivo y sostenible

2. Fortalecer las asociaciones para un desarrollo compartido

3. Consolidar el sistema nacional de cooperación internacional para el desarrollo

Los cuales, si bien se condicen, no son exactamente los mismos Objetivos Estratégicos definidos en la ficha de Definiciones Estratégicas año 20152018 presentada a DIPRES (2016) lo que, muy posiblemente, se deba a que los últimos son mucho más específicas y fáciles de medir mediante indicadores que las primeras, los cuales son descritos de forma más genérica. Ahora bien, respecto a cada objetivo definido en la Estrategia, el primero (afectado directamente por los criterios "fortalecimiento de la democracia" y "desarrollo inclusivo y sostenible"), más que nada establece define, en términos un poco más prácticos, un marco de acción para la ejecución de proyectos de cooperación, el cual (al menos aparentemente) da cuenta de la gestión que AGCI realiza hoy, lo que podría interpretarse, como un esfuerzo por afianzar el camino recorrido por el organismo.

El segundo objetivo estratégico, se sub-divide en 3 áreas temáticas "Desarrollo inclusivo y sostenible hacia la reducción de brechas estructurales y vulnerabilidades" y "Formación en América Latina y el Caribe" y "Proyección de la Cooperación Chilena", todas las cuales plantean nuevos desafíos para la gestión de proyectos d cooperación, aunque, al menos la primera, es ambigua al momento de expresar claramente cómo superarlos,

El tercer objetivo estratégico, reconoce la existencia e importancia de un sistema de cooperación y se hace cargo de las deficiencias en materia de gestión de la información y de educación para el desarrollo, sin embargo, no propone cursos de acción para consolidar el sistema y superar las brechas en materia de articulación inter-institucional, ni propone la consolidación de un sistema de educación para el desarrollo (articulación con la academiam , solamente establece la necesidad de optimizar los flujos de información utilizando los canales formales ya existentes (sitio web). Si cabe destacar, dentro de este objetivo, la propuesta de elaboración de una memoria anual para el seguimiento del cumplimiento de los objetivos definidos.

Por último, la Estrategia de Cooperación, define las modalidades e instrumentos de cooperación a utilizar por AGCI, entre los que se incluye a la Ayuda Humanitaria, lo que podría ser un reconocimiento de este ámbito de acción como parte de la cooperación internacional otorgada por Chile, sin embargo, como ya se ha expuesto, la Agencia no cuenta con una estructura y/o un programa específico que se haga cargo de dicho tema (salvo por el Fondo Chile contra el Hambre y la Pobreza, aunque este no pertenece a exclusivamente a AGCI y no es la única herramienta mediante la cual Chile entrega Ayuda Humanitaria), por lo que, parece más una declaración de voluntad, que un compromiso de hacerse cargo de dicho ámbito.

A modo de conclusión, respecto a ambos instrumento estratégicos, solo queda mencionar que, a pesar de su génesis, no esta tan claro que, tanto la Política, como la Estrategia, operen como una guía para el sistema de cooperación en su conjunto, tanto a nivel central (órgano rector), como a nivel sectorial (resto del sistema nacional), sino más bien parecen ser exclusivamente de AGCI, por lo que aún queda pendiente que sea institucionalizado al interior del sistema.

\section{Recomendaciones}

En primer lugar, para iniciar cualquier proceso de modernización institucional mayor al interior del Estado de Chile, es de primera necesidad tener el apoyo de un "campeón político" en la cúspide gerencial de la Agencia o del MINREL. Este, debe ser capaz de vincular a la estructura de adaptación del sistema organizacional con el macrosistema público, entregando un "ímpetu político para llevar acabo las la transformación del sistema y que ayude a posicionar el perfil de AGCI a nivel de gobierno" (Comité de Ayuda al Desarrollo, 2013), a fin de materializar y formalizar los ajustes y transformación que el órgano rector requiere.

En términos estructurales, es necesario actualizar el organigrama de la AGCI, a fin de regularizar las funciones y unidades que actualmente existen informalmente en la organización. Esto empoderaría 
a los funcionarios respecto a sus labores y a las líneas intermedias, para la adecuada supervisión del desempeño de funciones; adicionalmente permitiría formalizar metas y objetivos a cada nivel jerárquico.

Por otra parte, también es necesario mejorar la gestión de la información institucional y el desarrollo de métricas al interior de la agencia que den cuenta del cumplimiento de los objetivos estratégicos institucionales y de la política de cooperación a fin de ser un aporte para la toma de decisiones. Dichas métricas deben gestionarse transversalmente a fin de afianzar los flujos de información interdepartamental.

Respecto a la administración de los vínculos con los actores del sistema, la gestión de stakeholders no implica sólo el resguardar los vínculos existentes, también es necesario monitorear el mapa y verificar la posible inserción de nuevos actores. Al respecto, es necesario que el área encargada de administrar la relación con los sectores nacionales verifique la gestión de cooperación autónoma realizada por los mismos, identificando los demás actores con los que se relacionan para su ejecución.

A nivel de Estrategia, esta parece ser un buen elemento de diagnóstico, pero aún adolece de especificidad en términos de los objetivos que plantea alcanzar de aquí al 2018 y más aún de los mecanismos a utilizar para supervisar su logro, por lo que es necesario que se vinculen los mecanismos de control de gestión formales con dicho documento mediante la definición de objetivos específicos medibles (idealmente cuantificables), a fin de poder realizar un seguimiento periódico relativamente objetivo que vaya más allá de la elaboración de una memoria que puede dejar espacio a interpretaciones.

A nivel de definición programática, es necesario formular programas sectoriales de cooperación en los cuales se definan áreas o temáticas prioritarias (como salud, educación, desarrollo social, minería etc. La programación general sectorial deberá ser elaborada en conjunto con los demás actores nacionales (ministerio y servicios públicos, academia, ONG. etc.), privilegiando las posturas de los distintos ministerios de línea, a fin de tener claridad respecto a las capacidades (fortalezas) y disponibilidades del sistema chileno para la formulación de la oferta nacional e cooperación.

En esta misma línea, y en lo referido a la planificación territorial, debe desarrollarse anualmente y profundizarse aún más, alineándola explícitamente con la política y estrategia de cooperación, así como con la política exterior, a fin de definir zonas geográficas prioritarias para el sistema de cooperación nacional. El documento resultante debe ser difundido internamente y presentado, o al menos debe estar al alcance de los demás actores del sistema. El desarrollo de este instrumento puede apoyar a la aplicación de otras herramientas de coordinación sectorial, a fin de priorizar selectivamente el apoyo a actividades alineadas.

Respecto a los instrumentos de planificación presupuestaria, se recomienda generar un proceso transversal y uniforme para la elaboración presupuestaria que involucre a todas las unidades, utilizando como principio rector la alineación a los objetivos estratégicos definidos y a la estrategia y política de cooperación. En concordancia, también es necesario contar con el apoyo del agente o "campeón político" para apoyar la negociación de posibles aumentos presupuestarios en aquellas áreas estratégicas que se requieran.

Sobre el nivel estructural, en la agencia no existe una subdivisión (área o unidad) operativa encargada de la programación y/o ejecución del monitoreo y seguimiento, ni de la evaluación de la cooperación otorgada, tampoco existen programas de esta naturaleza. En este sentido, es necesario crear la estructura (formal) encargada de esta tarea y desarrollar una metodología de monitoreo y seguimiento de programas y proyectos de cooperación, recurriendo a la experiencia y buenas prácticas internacionales.

A nivel operativo, es necesario desarrollar nuevas herramientas de diseño de proyectos diferenciadas, que puedan ser utilizadas dependiendo del tamaño y necesidades de cada proyecto. Así, el instrumento de marco lógico (el único que se utiliza en la actualidad) debiese ocuparse exclusivamente en la formulación de proyectos de mayor envergadura y para los demás se pueden ocupar otro tipo de metodologías abreviadas. Para el desarrollo de dichas herramientas, es posible recurrir a la experiencia y buenas prácticas internacionales, solicitando apoyo a los socios de cooperación de la AGCI.

En línea con lo anterior, también es recomendable revisar el adecuado uso de los instrumentos de formulación de proyectos aplicados actualmente en AGCI, a fin de permitir el correcto monitoreo y evaluación de dichos proyectos. Esta actividad puede ser realizada por la misma unidad de monitoreo y seguimiento que se recomienda instalar.

En términos de gestión, coordinación y desarrollo de la cooperación desarrollada por organismos privados y de la sociedad civil, se recomienda, tal como comenta Ana María Portales (2015), fortalecer y desarrollar nuevos mecanismos, líneas presupuestarias e instrumentos que fomenten el surgimiento de 
asociaciones público-privadas para la cooperación internacional, en línea con las prioridades definidas en el Foro de Alto Nivel para la Cooperación Eficaz al Desarrollo. Por supuesto, es fundamental que la aplicación de dicha modalidad esté definida en la política de cooperación, a fin de tener claridad sobre el cómo y el cuándo es útil y deseable utilizar dichas asociaciones. Adicionalmente, se debe considerar tanto el desarrollar programas y proyectos en conjunto con unidades de Responsabilidad Social Empresarial, la Academia y ONGs; como apoyar el desarrollo de proyectos de cooperación autónomos, gestionados por instituciones de la sociedad civil, siempre que se encuentren alineados con las directrices sectoriales y geográficas definidas por la Agencia, considerando la experiencia internacional en esta materia.

\section{Referencias}

Banco Mundial (2013). La Formulación de Políticas en la OCDE: Ideas para America Latina.

Colacrai, M. D., Kern, A., Pattacini, V., Weisstaub, L., y Vallone, M. (2009). Escenarios y Desafios de la Cooperación Sur-Sur a 30 años de la Declaración de Buenos Aires: Lo viejo y lo nuevo para conceptualizar la cooperación sur-sur. Aportes conceptuales y recomendaciones para la política Argentina. Universidad Nacional de San Martin, San Martín, Argentina.
Comité de Ayuda al Desarrollo (2013). Special Review of Chile.

Domínguez, R. y Olivié, I. (2014). Retos para la cooperación al desarrollo en el post-2015. Estudios de Economía Aplicada, 32(3):995-1020.

Katz, D. y Kahn, R. (1977). Psicología social de las organizaciones. Trillas, México.

Mielniczuk, F. (2013). BRICS in the Contemporary World: changing identities, converging interests. Third World Quarterly, 34(6):1075-1090.

Mintzberg, H. (1988). La estructuración de las organizaciones. Ariel, Barcelona.

OCDE (2010). Organización para la Cooperación y el Desarrollo Económicos. Perspectives on Global Development 2010. OCDE Development Centre, París.

Pacheco, J. F. (2012). Apuntes de trabajo. ILPES.

RACI (2012). Manual de Cooperación Internacional â Una herramienta de fortalecimiento para las organizaciones de la sociedad civil (OSC).

Sumner, A. (2010). Global Poverty and the New Bottom Billion: What if ThreeâQuarters of the World's Poor Live in Middleâincome Countries? IDS Working Papers, 2010(349):1-43. 